\title{
Clases y movimientos sociales en El Salvador: caracterización, desarrollo e intervención
}

\section{Segundo Montes}

Exposición tenida en el VIII CONGRESO CENTROAMERICANO DE SOCIOLOGIA, Gualemala, 10-15 de oclubre de 1988; Mesa Redonda No. 2: CLASES Y MOVIMIENTOS SOCIALES EN CENTROAMERICA; CARACTERIZACION, DESARROLLO E INTERVENCION).

\section{Introducción}

El tema propuesto para esta mesa de trabajo es fundamental no sólo para una discusión académica que busque depurar los conceptos y las calegorias, sino también para cualquier estudio sociológico que tenga como pilar el conocimiento de las estructuras para el análisis de las coyunturas y de los procesos socio-politicos. En mi intervención se pretende incursionar en la estruclura social de El Salvador, así como los otros expositores lo harán en la de sus respectivos palses de la región.

En la primera parte de mi trabajo intentaré un análisis estructural de las clases sociales existentes hoy en dia en El Salvador, asi como de las divisiones y subdivisiones de las mismas. En la segunda me propongo describir el comportamiento de las diferentes fuerzas sociales en la presente coyuntura, considerada como de "crisis orgánica" de acuerdo a la calegoria gramsciana.

\section{Anallsis estruclural de las clases soclales}

Tomando como base los elementos analíticos de Marx en sus obras históricas, o la formulación más depurada y leórica de Lenin (Lenin, 1961, 242), asl como los nuevos elementos aportados por autores de diversas corrientes de pensamienlo y sus críticas respeclivas (Gurvitch, 1971, 234), estimo indispensable considerar -después de un esfuerzo de 
cuanlificación de los inlegrantes de cada clase y de las divisiones y subdivisiones a su interior - tres elementos en la esiructura de clases de El Salvador en la realidad histórica presente: 1 la posición que ocupan en el concreto modo de producción y las relaciones sociales que de él se derivan, que es el elemento más material, estructural y objetivo; 2) la percepción que tienen de la realidad anterior las distintas personas y grupos, que es un elemento más subjelivo y vinculado con la alienación; 3 la conciencia de clase y su opción consecuente, que es un elemento subjetivo-objelivo de comportamiento socio-polílico. El desarrollo histórico de las estructuras y de los diferentes grupos sociales, en su triple dimensión, va a conducir a la composición estruclural de las clases sociales $y$ al comportamiento de las diferentes luerzas sociales en períodos y momentos históricos determinados.

Los criterios en principio simples para delerminar el primer elemento. más objetivo y malerial, la propiedad de los medios de producción o de la sola fuerza de trabajo, en la realidad concreta e hisiórica no son suficientemente operalivos en una determinada formación económicosocial, y obligan a divisiones y subdivisiones de calegorias para describir la estructura de clases salvadoreña (PCS, junio de 1980, 28-43). Presentaré primero un esquema descriptivo y cuantitativo de las clases y sus divisiones, para luego analizar en ellas los tres elementos aludidos.

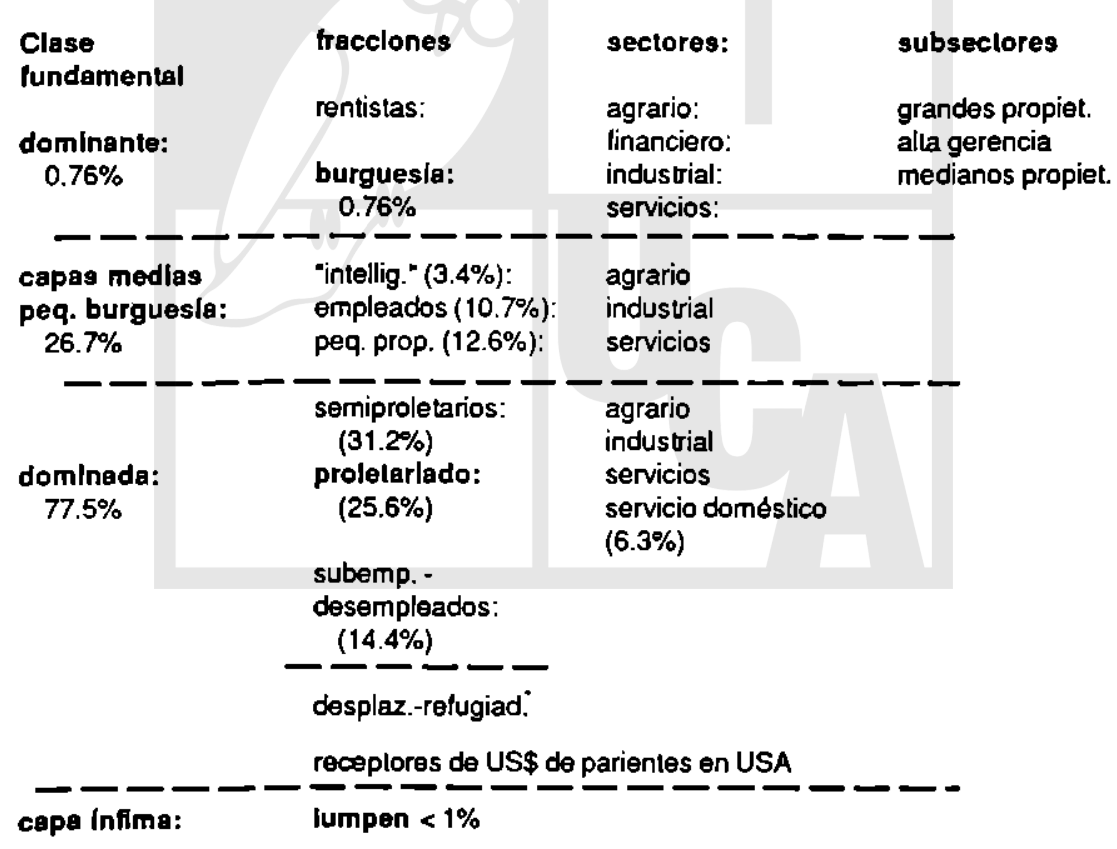




\section{Caracterlzaclón y cuantlificaclón por categoria:}

Dejando a un lado la discusión más leórica - y aquí menos imporlantede si son, o no, del todo correctas las categorias adoptadas para las subdivisiones (capas, 1racciones, seclores y subseclores), dediquémonos a ver si el esquema presentado responde a la composición social salvadorefia actual, y apliquemos a cada uno de esos grupos los tres elementos analíticos propuestos anteriormente.

En primer lugar, hagamos un esfuerzo por cuantificar cada uno de los grupos, aproximándonos lo más posible a la realidad en cuanlo los escasos datos lo permiten.

\subsection{Clase fundamenlal dominante:}

La fracción de los rentistas es práclicamente desconocida. Si puede haber disminuido en el sector agrario, por la aplicación de la Fase I de la reforma agraria, lo más probable es que se haya incrementado con la presente crisis del pais, a consecuencia de la que varias personas pueden haber colocado sus capitales en la banca, en bienes raíces, en acciones, en la bolsa de valores, o en editicios de alquiler, ya sea en el extranjero, ya sea en El Salvador mismo, para vivir holgadamente de lo que les renten o produzcan. La falta de registros adecuados, de investigación pertinente, o la confidencialidad misma de los datos impiden que se pueda conocer su magnitud, si bien no puede ser muy grande el número de tales personas ubicadas en la cúspide de una obtusa pirámide de la estruclura económica que por su propio desarrollo tendia a suprimir esa calegoria o transiormarla progresivamente en burguesia.

En la fracción de la burguesía se han introducido algunas modificaciones en el sector agrario, como consecuencia de la Fase I de la reforma agraria - como en el financiero, por la reforma bancaria. No obstante, el número afeclado en el primero es muy reducido, no sólo en valores absolutos, sino también en cuanto a expulsarlos de esa fracción, por el hecho de haber podido conservar parte de su propiedad en virtud del "derecho de reserva", y haber podido derivar el valor de lo expropiado, mediante el dinero o los bonos, a otros sectores incluso más rentables de la economía. En cuanto al segundo, la relorma bancaria no despojó de loda la propiedad, sino de una parte de la misma, en favor de nuevos accionistas, del estado o de los empleados que quisieran y pudieran adquirirla, pasando más bien la administración y el conłrol de la banca a manos del estado, mientras que parle de la propiedad que no había sido descapitalizada se mantuvo, o la indemnización liberó fondos para invertir en otros sectores o para expalriarlos al extranjero.

En el subsector de los "grandes propietarios" ubicaremos a las empresas privadas "gigantes" y "grandes", que suman un total de 2,271 
(Montes,1984, 199, Cuadro I), de las que 1,941 correspondian al sector agropecuario, 126 al del comercio, 102 al de la industria, y las 102 restantes al de la banca y demás servicios (lbidem, 200, Cuadros III y IV;Sevilla, 1984, 168 y 170, Tablas No. 8 y 9) para antes de las "reformas", pero cuya composición, como se ha explicado anles, no ha variado sustancialmente. En efecto, por el Decreto 154, aplicado a la Fase I de la reforma agraria, se afecló nada más a 470 propiedades agropecuarias $(24.2 \%$ de las giganles y grandes propiedades: PERA, 1985, 5). Ahora bien, suponiendo que cada propiedad corresponde a una familia - lo que no parece ser muy exacto, al menos en las propiedades agropecuarias, donde las de 500 Has. y más eran sólo 206 (Thome, 1984, 238), pero las alectadas por el Decreto 145 que tomaba esa misma extensión de lerreno fueron más del doble, 470, algunas de ellas por confusión o abuso, pero las más por perlenecer varias un mismo propletario; $y$ algo similar se puede asumir para los demás sectores, en los que algunas empresas, lal vez, serán de propiedad asocialiva, pero también hay familias propietarias de más de una empresa; más aún, en los diversos seclores hay diversilicación de la propiedad de una misma familia (Colindres, 1977; Sevilla, 1984)—; suponiendo, repilo, que cada propiedad corresponde a una sola familia, y sobre la base de aproximadamenle 800,000 familias en El Salvador en las fechas de los dalos (Montes, 1988a, 82-89, 133), los grandes propietarios apenas alcanzarian el $0.28 \%$ de las farnilias salvadorenias, de los que en el sector agropecuario -en caso de no ser propietarios también en olros sectores - se concentraría el $0.24 \%$ de las lamilias, en el de la induslria el $0.013 \%$, en el del comercio el $0.016 \%$ y en el resto para finanzas y demás servicios el $0.013 \%$ de las familias del pais. La concentración de varias propiedades en una sola familia reduciría aún más los porcentajes para loda la población salvadorefía.

El subsector de la "alia gerencia" es más dilicil de definir, sobre todo en economias subdesarrolladas en las que la "clase gerencial". no hâ adquirido ni el crecimiento ni la relevancia que en los países más desarrollados, lanto en número como en poder de decisión en la economía. Comprenderíamos en ese subsector, para el caso salvadoreño, a los altos prolesionales que tienen gran inllujo en la empresa, ya sea como asesores, como alios gerenles o en olros pueslos importanles en la dirección de la empresa, con relativa capacidad de decisión, allos honorarios. participación en las utilidades, y algunas veces coparticipación en la propledad o relribución en forma de acciones. En tales condiciones estimo que no se da el caso para el seclor agropecuario, sino casi exclusivamente en los otros sectores, sobre todo en las "empresas gigantes"; suponiendo que para cada gigante hubiera dos personas de tal categoría, y una para cada "empresa grande", tendriamos un total hipotético y máximo de 476 personas de "alla gerencia" $(0.06 \%$ de las familias salva- 
dorefias), cilra que probablemenle es mucho menor, por la definición adoplada, por la repelición de algunas personas en varias empresas, o por no dislinguirse en algunos casos de la familia misma de los propietarios (hijos, yernos o parientes muy cercanos). Restaría agregar la "alta gerencia" del sector público, que se limitria a unos pocos administrativos de máximo nivel en las entidades autónomas productivas del eslado, cifra que no alteraria signilicativamente los dalos anleriores.

Por último, en el subseclor de los medianos propietarios se considera a todos aquellos que tienen una propjedad para la que contratan mano de obra y obtienen una reproducción ampliada del capilal. Los limites son difíciles de definir, pero nos atendremos a la categoría de "medianas empresas", con las debidas precauciones: 3,350 en tolal, de las que 2,238 seríañ del sector agropecuario (Monles, 1984, 199-200, Cuadros I y III). Suponiendo otra vez que cada propiedad pertenece a una familia distinla, y que ninguna de estas propiedades corresponde a dueño alguno de propiedades mayores, lendriamos un $0.42 \%$ de familias salvadorefias en esie subsector $(0.28 \%$ en el seclor agropecuario).

Partiendo de las categorias adoptadas para este trabajo, en la clase fundamental de la burguesía salvadorefia se podria incluir hasta una proporción máxima hipotética del $0.76 \%$ de las tamilias salvadorefias, aunque presumiblemente la cantidad y proporción será aún menor por la concentración de varias propiedades de un mismo sector, y de propiedades de varios sectores a la vez, en algunas de esas familias.

\subsection{Clase fundamental domlnada:}

El semiprolelariado se puede encontrar en todos los sectores, ocupado en muchios casos en el "sector informal" de la economia; pero estriclamente considerado es más aplicable al agrario, donde los insuficientes Ingresos oblenidos en la parcela tienen que ser complementados con la venta parcial o lemporal de la luerza de trabajo, y en ese sector no sólo es más medible con los datos de que se dispone, sino también es mayorilario respecio a los otros seclores - en los que se puede confundir con el "subempleo". De las 249,163 microempresas existentes en El Salvador, 234,941 serian microexplolaciones agropecuarias (Montes, 1984, 199-200, Cuadros I y III). La reforma agraria no ha modificado sustancialmenle esas cifras, pues la Fase III lo que ha hecho es convertir algunas microexplotaciones de arrendamienlo en microexplotaciones en propiedad, con un promedio de 1.5 Has. por beneficiario que generan trabajo para 48.6 dias laborables al año en promedio (Montes, 1986, 247-249). que los conserva como semiproletarios. Si se manliene el mismo supuesto de que cada microempresa corresponde a una familia distinta -más verosimil aquí que en las gigantes y grandes-, estarian comprendidas en esla categoría $31.15 \%$ de las familias saivadorenas. 
En el prolelariado, que es la fracción más propia y específica de la clase dominada en un modo de producción capitalista, debemos atenernos a los datos disponibles, no del todo coincidentes entre sí. Toda la empresa privada salvadorena generaba (años 1978-79) 214,212 empleos remunerados, de los que 87,033 correspondian al sector agropecuario; ahora bien, si se eliminan los administrativos y lécnicos -que corresponden a las capas medias, no al proletariado estricto-, y que sólo para las empresas no agropecuarias con 5 o más trabajadores pueden ascender a unos 27,000 (Montes, 1984, 199-202, Cuadros I-VI; Sevilla, 1984, 168-172, Tablas No. 8-10), podríamos considerar unos 180,000 prolelarios para el tolal, de ellos unos 85,000 para el sector agropecuario (22.5\% y $10.6 \%$ respectivamente de las lamilias salvadorenas, suponiendo también que cada trabajador representa a una diferente familia, lo que no es el caso en los diversos sectores, dado que más de un miembro de la familia, de distinto o del mismo sexo, tiene trabajo remunerado); pero si se agregan unos posibles 25,000 propiamente dichos proletarios del sector público -como se analizará en las "capas medias" en el sector de los "empleados"-, el total del proletariado podría elevarse a unos $205,000(25.6 \%$ de las familias salvadoreflas, suponiendo que cada uno representa a una distinta). Si en 1979 todos los sectores, excluido el agropecuario, generaban 218,171 empleos (Montes, 1984, 201-202, Cuadros V y VI), a los que habría que agregar los escasos cotizantes al Seguro Social del sector agropecuario que trabajan en la agroindustria, la cilra serla baslante coincidente con los 225,500 colizantes en ese mismo ano (Montes, 1988a, 139, Cuadro XXVII), de los que no lodos son proletarios, sino empleados, familiares no remunerados, e incluso propietarios y accionistas.

La iracción de subempleados y desempleados es aún más diticil de cuantificar con exactitud o aproximación. Si en 1980 se consideraba como del $55 \%$ y $16.1 \%$ de la PEA respectivamenle, en 1985 el desempleo abierto se elevó al $33.7 \%$ y el. subempleo superaba el $40 \%$ según estimaciones. Ahora bien, dado que los criterios para determinar la PEA son cuestionables, es más realista calcular las cifras absolutas de desempleados y subempleados en base a la PEA reconocida y a los porcentajes oficiales en ambas categorlas (Montes, 1988a, 83-87, Cuadros V y VIII): en 1980 habría 259,371 desempleados y 886,050 subempleados, mientras que en 1985 los desempleados se elevaban a 603,840, y los subempleados a por lo menos 754,800; suponiendo que cada uno de ellos representa una familia distinta, la suma de ambas cifras superaría las familias de El Salvador en las mismas techas, por lo que hay que considerar un minimo de 2 miembros de la PEA por familia, en cuyo caso los desempleados representarian al $14.4 \%$ de las familias de 1980 y al $27.4 \%$ en 1985 , mientras que los subempleados al $\mathbf{4 9 . 2 \%}$ de las lamilias 
en 1980 y al $34.3 \%$ en 1985 . Sin embargo, en esta fracción, para eleclos de cuantificación, estimo que sólo hay que lomar en cuenta a los desempleados -quienes disponen únicamente de su fuerza de trabajo, pero no pueden venderla porque el sislema no ofrece sulicientes pueslos de trabajo para la población-, pues gran parte de los subempleados corresponden al mismo tiempo a la iracción de semiproletarios, o incluso a algunos pequefíos propietarios que ternporalmente buscan trabajo -ellos, 0 algún miembro de su grupo familiar, para incrementar los escasos ingresos que les produce el precario medio de producción.

En todas estas fracciones se da una subdivisión por sectores. Pero hay aquí uno que merece especial consideración, el del servicio doméstico: en 1971 el $33 \%$ de la PEA temenina del departamento de San Salvador trabajaba en ese rubro, y en 1980 el $19.9 \%$ de la PEA femenina del pais trabajaba como doméstica o como familiar no remunerada, con mayor incidencia entre los 10 y los 24 años de edad (Sermeño, 1988, 29).

La guerra civil, la represión desalada, las muertes violentas y las migraciones forzadas que se derivaron, han producido cambios en la composición social salvadorefía. El aproximadamente medio millón de desplazados internos, dẻ conformidad con la tasa de miembros por grupo familiar entre los concentrados, de 5.5 personas por jefe de familia, representaria a 90,909 familias - $9 \%$ de las tamilias del país en esos años-(Instituto, 1985, 35-37, Cuadros 18 y 22). Si bien esta cantidad y porcentaje no hay que agregarlo al reslo de categorias, porque en su inmensa mayoria eran pequefios propietarios y semiproletarios (Ibidem, 193-217), en el proceso se han convertido en una categoria especial: por un lado los manliene como desempleados o subempleado -integrándose cada vez más al sector informal de la economia-, pero que por olro lado es asistida humanitaria y gratuitamente con alimentos y algunos otros bienes de consumo básico ¿ La tendencia, por lo tanlo, es que una parte de esa población desplazada relorne a sus lugares de origen si se da una solución al conflicto en fecha no muy lejana, pero la mayoria se irá inlegrando al sistema formal y, sobre todo, informal de la economia y de la sociedad marginal (Instituto, 1985; 1986). Algo similar puede afirmarse de los relugiados en el área centroamericana, especialmente los que emigraron familiar y colectivamenle a Honduras y una parte de los emigrados a Nicaragua, Cosla Rica, Panamá, Guatemala y Belize, que podrian tolalizar unas 100,000 personas, representando un $1.8 \%$ de las familias salvadorefías en esos años (Instituto, 1985, 35, Cuadro 18). Para el resto de los refugiados en el extranjero la situación es diferente, no sólo por el hecho de que provengan en gran mayoria de fracciones diversas y capas medias, sino porque predominantemenle es un miembro del grupo tamiliar el que ha emigrado, a veces acompañado, precedido o seguido por 
algún otro miembro, pero no la familia entera, que en su núcleo fundamental ha permanecido en el pais; de todos modos, se trata de una cantidad adicional de unos 150,000 sin tomar en cuenta los emigrados a los Estados Unidos (lbidem).

Brevemente es necesario considerar un fenómeno de gran trascendencia para la composición económica y social de El Salvador en el presente. El $35.56 \%$ de las familias salvadorefnas reconocen tener parientes en los Estados Unidos (Monles, 1987, 32), pero como un $32 \%$ de las mismas no recibe ningún envío de dólares de los emigrados a los Estados Unidos, hay un $24.18 \%$ de las familias salvadorefias que dicen que sí reciben remesas monetarias de sus parientes emigrados allá, lo que representa un promedio de US\$188 mensuales para las familias que reciben dinero de sus parienles emigrados a los Estados Unidos (Montes, 1987, 113, Cuadro XXII, en comparación con datos de pág. 32). Esle grupo de familias no es ninguna tracción especial y distinta de las demás, sino que pertenecen a las distinlas fracciones, capas y sectores, aunque su ubicación se puede haber modificado en el conjunto de las categorías por las remesas recibidas con las que pueden tener acceso a bienes de consumo y/o de producción, ya sea en el sector formal o en el informal de la economía salvadoreña.

\subsection{Capas medias:}

En las capas medias tenemos en primer lugar lo que se puede denominar como "intelligentsia", que comprendería a 3,561 prolesores e inslructores universitarios, $/, 525$ miembros de asociaciones profésionales, por lo menos 1,000 "profesionales" que trabajan en medios de comunicación social, y un minimo de 20,000 maestros (Montes, 1984, 175-186); para un tolal de 32,086 personas, que de representar cada una a una familia diferente, podrian equivaler al $3.4 \%$ de las lamilias salvadorefias. Las cifras tendrian que ser depuradas, en primer lugar por el hecho de que varias de esas personas ocupan más de un puesto y/o trabajan además como "empleados públicos", en segundo lugar porque no todas las pertenecientes a esas prolesiones y trabajos están afiliadas a las asociaciones contempladas en los datos; por todo ello, posiblemente el conjunlo absoluto se adecúe baslante a la realidad, aunque el valor porcentual tiene que ser menor por el hecho de que en esas familias ha de Irabajar más de una persona.

En cuanlo a la categoria de "empleados", el sector público en 1985 ocupaba a 118,534 personas (Monles, 1988a, 137, Cuadro XXIV), de las que habria que excluir todas las que trabajan en la categoría de "intelligentsia", más las que son propiamente proletarios, tanto en el gobierno central como en las instiluciones aütónomas y municipalidades, con 10 que la cifra total de empleados estimo que no sobrepasará los 75,000 , in- 
cluídos los miembros de las Fuezas Armadas, -que de represemlar cada uno una familia dilerente, lo que no será el caso, significarla el $7.9 \%$ de las familias salvadorefias-; si se agregan los aproximadamenle 27,000 administralivos y técnicos ocupados por la empresa privada (Montes, 1984,201 , en base a Cuadro V) - suponiendo que ninguno de ellos está comprendido ya en otra Iracción, y que represente a una familia distinla-sumarian otro $2.8 \%$ de las familias salvadorefias.

La última categoria denlro de las capas medias viene dada por los pequefios propielarios. Son los que tienen medios propios de producción, pero que no pueden lograr una reproducción ampliada del capital, y que normalmente ni conlralan fuerza de trabajo ni venden su propia fuerza de trabajo; es decir, se trata de una economia familiar y de subsistencia, en la que muchas veces se estima como ganancia o beneficios los salarios disfrazados, tal vez inleriores incluso a los vigentes en el mercado laborat. De acuerdo a los dalos disponibles, en El Salvador habia un total de 77,843 "empresas pequenas" -de ellas 31,748 en el seclor agropecuario-, que junto con las "microempresas" creaban un puesto de trabajo remunerado por cada tres de ellas (Montes, 1984, 199-200, Cuadros 1 y III), lo que representaría, en el mismo supueslo de empresa por tamilia, $9.7 \%$ de las familias salvadorefias ( $3.9 \%$ con pequeña propiedad rural) comprendidas en esta calegoria. La reforma agraria, por su parte, ha modificado ligeramente la composición, al convertir a los beneficiarios de la Fase 1 en pequefios propietarios (algo más de $6 \mathrm{Has}$. por beneficiario directo) cuando anteriormente eran proletarios rurales o subempleados - los beneficiados con la Fase III se mantienen como semiprolelarios, cambiando de arrendalarios a propietarios de parcelas de 1.5 Has. en promedio-, con lo que los 27,456 beneficiarios directos de la Fase I de la reforma agraria habrán incrementado en $2.9 \%$ las familias comprendidas en esta categoria (Montes, 1986a, 247, Cuadro I).

\subsection{Capa inflma:}

Reslaria únicamente cuantificar las personas ubicadas en la capa intima o lumpen, para lo que carecemos de datos confiables; de lodos modos no representa una proporción significativa en la sociedad salvadoreña, como "prolesión" - no como acción esporádica para sobrevivir-, pues la inmensa mayoria de desempleados, subempleados, des-

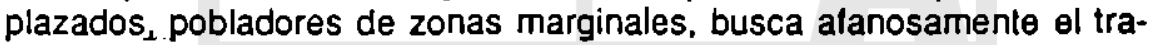
bajo o medios dignos de subsistencia, la mayoría en el expandido sector informal de la economía. Estimo que los que constituyen el lumpen estriclamente considerado no alcanzan ni el $1 \%$ de la población de El Salvador.

Como resultado de todos los cálculos realizados para aproximarnos lo más posible a una cuantificación de las diversas categorias, con todas las 
precauciones y limilaciones ya señaladas, hemos alcanzado un $105.96 \%$ en la suma de las mismas, lo que muestra que los cálculos no pueden ser del todo correctos y que hay sobreeslimación en algunas categorias -a pesar de que no se han incluido los desplazados, entre otros.

Ahora bien, como hemos supuesto que cada persona represenlaba a una familia, cosa que no ocurre en algunos grupos sociales, olro cálculo más verosímil —que me ofrece más credibilidad, y por ello lo tomaré como crilerio más probable y conliable para el resio del trabajo-, basado en la población adulta y que en realidad debia ser considerada económicamente activa, que comprende algo más de la mitad de la población del país (Montes, 1988a, 83-86), nos daría la siguiente distribución porcentual, de acuerdo a los mismos dalos y categorias adoplados anteriormente:

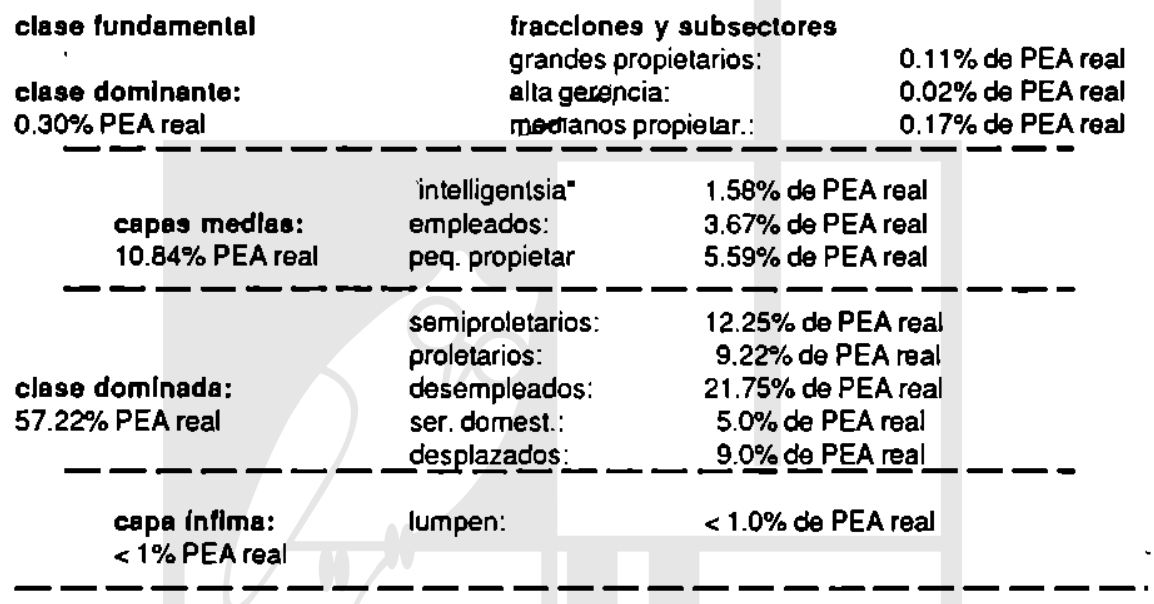

Para el seclor del "servicio doméstico", en base a los datos disponibles, si el $19.9 \%$ de la PEA femenina del país trabaja en 1980 en eso o como familiar no remunerado, supongo que se puede dividir en partes iguales, y dado que las mujeres constituyen aproximadamente la mitad de la población, habría un $5 \%$ de la PEA total real trabajando en el servicio doméslico. En lodas las categorías relacionadas con el empleo, fuerza laboral, elc. no hay dilicultad en los cálculos, relacionados con la PEA real; donde se puede objetar el mélodo es en las relacionadas con la propiedad, en las que hemos lomado cada una como representativa de la fueza de trabajo de cada familia. Para la grande y mediana propiedad estimo que es válido, pues consta por diversas fuentes que en promedio cada lamilia posee más de una propiedad —como se vio en la aplicación 
de la Fase I de la relorma agraria-, con lo que se equipararía la cantidad de propiedades con la PEA real de las familias propietarias; para la pequeha propiedad, ciertamente en las de la Fase I ni siquiera hay trabajo todo el afio para los beneficiarios direclos -180 dias al año en promedio (Montes, 1986, 249, Cuadro III)-, y para el resto de propiedades posiblemente no sea muy diterente en una parte de los casos, aunque ahi puede estar subestimada la proporción de la PEA real represenlada.

El lotal de los rubros anteriores arroja un $69.36 \%$, quedando el $30.64 \%$ que se distribuiria entre rentistas, subempleados, refugiados y otros no contemplados en las calegorías bien delinidas, o sería un ajuste a las estimaciones realizadas en cada una o en alguna de ellas.

\section{Posición que ocupan en el modo de producción y rela- clones soclates derivada de ella:}

En la parte anterior se ha procurado cuanlificar las diversas categorias que integran la estruclura social salvadorefía. Si las dos clases fundamentales, y las Iracciones de clase correspondienles más estrictamenle al modo de producción capitalisla, son, por un lado,"la burguesia, que abarcaría nada más el $0.3 \%$ de la PEA real del pais $-y$ consiguientemente de la población y de la sociedad-y, por olro, el proletariado se extendería nada más al $9.22 \%$ de 10 mismo, se explica el que se cuestione cuál es en realidad el modo de producción dominante en E. Salvador (Montes, 1983, 30-37, 231-235).

El lugar que ocupan en el modo de producción, y las relaciones sociales que de ahi se derivan, no es algo uniforme ni homogéneo."En la clase dominante ciertamente el lugar que ocupan las diversas fracciones, y todas las subdivisiones comprendidas en la misma, es bastante homogéneo, como propielarios de los medios de producción, ya sea en forma dinámica, como en la burguesia, ya sea en lorma pasiva, como en los rentistas -incluso la "alta gerencia", aun en el caso de que no tenga participación en el capital, de hecho ejerce funciones determinantes en la producción, casi a modo de "propietario"-; en cuanlo a las relaciones sociales, son en esta clase predominantemente capitalistas, con una ausencia cada vez mayor de los verdaderos propielarios en las relaciones directas con la fuerza de trabajo, mediadas por personal administrativo; antagónicas con la clase opuesta y en lucha con ella.

En la clase dominada, por el conlrario, la posición en el modo de producción es sumamente helerogénea, así como diversas las relaciones sociales derivadas de ella. Los prolelarios ocupan un lugar especifico, claro y homogéneo, y sus relaciones con la clase anlagónica también eslán bien definidas por la lucha de clases - algo similar se puede aplicar a las iracciones de semiproletarios, subempleados y desempleados, cuando venden su fuerza de trabajo. En cambio, los semiproletarios - cuando no 
venden su fuerza de Irabajo- ocupan un lugar diverso en el sistema capilalista, dado que disponen de algún medio precario e insuficiente de producción, que les asegura en parle la reproducción de su fuerza de trabajo, e incluso venden parte de su producción en el mercado, torlaleciendo con ello no sólo la dinámica del sistema y la extracción de plusvalia por el mismo de múliples formas — constiluyendo o incrementando, además, el ejército laboral de reserva global-, sino también garantizando, en el sector rural, la mano de obra disponible en los periodos de más demanda para las planlaciones de produclos de exportación (Montes, 1986, 74-120). Los subempleados -en la medida en que no coincidan con los semiproletarios- y los desempleados constiluyen la masa mayor del ejércilo laboral de reserva, junlo con una Iracción de los desplazados; las relaciones sociales en el modo de producción, mienlras no vendan su fuerza de trabajo, son distinlas a las de los proletarios, y se mantienen a la espera-de oportunidades. El sector del servicio doméstico, por su parte, ocupa un lugar diferente en el modo de producción, ocupando liempos más prolongados de la jornada, compartiendo muchas veces la vivienda con los contralanles, recibiendo la relribución parle en dinero y parte en alimentación y otros servicios básicos; las relaciones sociales no son propiamente capilalistas, sino más personales -precapitalistas-, más de "servidumbre-sefiorio" —incluído en muchos casos el "derecho de pernada". Los desplazados, cuando no son contratados para algún tipo de trabajo, no ocupan lugar alguno en el modo de producción -ni siquiera en muchos casos participando en el mercado de adquisición de bienes-, sino a lo más en cuanlo ejército laboral de reserva, y son mantenidos con una vida precaria gracias a las donaciones internacionales; sus relaciones sociales, por tanlo, son diferentes, de dependencia de la asistencia humanitaria, unida a una dependencia ideológica y política creciente (Instituto, 1985; 1986). Por último, los que reciben remesas en dólares de sus familiares emigrados a los Estados Unidos, cuyo monto representa, en promedio, el $60 \%$ de todos los ingresos familiares, pero en muchas familias es a veces la única fuente de ingresos monetarios (Montes, 1987), en la medida y proporción en que tengan medios propios de trabajo y vida, o vendan su fuerza de trabajo, comparten la posición correspondiente en el modo de producción y las relaciones sociales derivadas del mismo; pero las remesas y su conversión los ubica en un lugar distinto del modo de producción - lal vez sólo en la circulación y el mercado, no siempre nacional-, y las relaciones sociales están vinculadas con ese hecho, tanto respecto a los contratadores de su fuerza de trabajo, como en la necesidad o no y la frecuencia de venla de la misma y de participación en el mercado de bienes y servicios; de hecho, en gran parle de ese numeroso grupo, las relaciones sociales son más bien con el mercado laboral y de bienes y servicios, asi como con las luchas de clases y étnicas en los Estados Unidos, por la mediación de los 
familiares que alli venden su fuerza de Irabajo y la reproducen bajo altas tasas de explotación y extracción de plusvalia, mientras que aqul convierten las remesas en un medio de reproducir la fuerza de trabajo de sus descendientes y de facilitar una especie de "seguro de ancianidad" para sus progenitores que posibilitaron su migración.

En las capas medias, por su parte, también existe una gran heterogeneidad. Mientras la "intelligenlsia" ocupa un lugar imprescindible para la reproducción ideológica del sistema y del modo de producción, en procura de un consenso y creación de la sociedad civil, los empleados ocupan un lugar también imprescindible en la producción y en el sistema, creando o posibilitando tanto la sociedad civil como la sociedad política; todos ellos, realmente, venden su fuerza de Irabajo y en cierto sentido podrían ser equiparados al proletariado, pero el lugar que ocupan ciertamente difiere -prescindiendo de su percepción y opción socio-polltica-, no sólo en la retribución económica y socjal, sino también en el trabajo mismo y en su posición objetiva diferenciada y dicolomizada; las relaciones sociales que de ahí se derivan, si bien podrian ser estrictamente laborales y de clase antagónica y explotada por la propielaria de los medios de producción o por el estado. son más bien de puente entre las clases antagónicas y de instrumentalización y mediación para someter a la clase proletaria y ayudar a la exiracción de la plusvalia. En cambio, la fracción de los pequehos propietarios ocupa un lugar distinto en el modo de producción, ordinariamente no contratando mano de obra asalariada, pero sí acudiendo al mercado a vender sus productos, por lo que en la realización de sus benelicios transfieren plusvalia al capilal, asl como en la adquisición de insumos, créditos y bienes de otra indole, al mismo liempo que explotan la fuerza de trabajo ya sea de ellos mismos ya sea de los familiares no remunerados que trabajan en esa propiedad; las relaciones sociales al interior del grupo laboral son normalmente de parentesco y de explotación de los menores, mujeres y parientes menos cercanos, mientras que hacia el exlerior son de competencia y lucha con los intermediarios y el capital, pero sin llegar a ser antagónicas mientras se mantenga, asegure y reproduzca la propiedad y economía familiar.

Respecto a la capa íntima -el lumpen-no sería preciso analizarla de manera específica en la sociedad salvadorefía, pues no parece presentar mayores dilerencias ni características peculiares frente a la de otras sociedades. Su ubicación está bien definida como escoria o desecho de la sociedad, que ella misma crea; las relaciones sociales que mantiene cón ella son las de aprovechar las oportunidades que aquélla le brinda y propicia a través de los mecanismos de represión, explotación y permisión de transgresiones a las pautas sociales aprobadas y reconocidas oticialmente. 


\section{Percepclón de esa realldad:}

Una cosa es la realidad, la posición que ocupan en el modo de producción y las relaciones sociales objetivas que se derivarlan de ella, y otra cosa es la percepción subjeliva e ideologizada que se tiene de esa realidad, conformando el ámbilo de la alienación o de la conciencia correcta.

En la clase dominante existe una percepción baslanle correcta de la realidad, aunque se den en su seno contradicciones secundarias, sublimadas ideológicamente en algunos medianos propietarios por la lucha y defensa de sus intereses - considerados como colectivos y homogéneos a toda la clase - frente a la clase antagónica y al ejércilo laboral de reserva. En cambio, en la clase dominada la percepción no siempre es correcla ni mucho menos homogénea: los semiproletarios en muchos casos no se sienten explotados por el capital de múltiples formas, sino que comparten una alienanción introyectada de propietarios de medios de producción, de diterenciación objetiva y de intereses con las demás fracciones; los proletarios, más claros y consistentes, al menos en el sector urbano y partes del rural, han ido adquiriendo una percepción cada vez más correcta - tal vez no todos los del "sector público", que en algunos casos pudieran considerarse a sl mismos como "empleados"-. si bien a su interior se dan núcleos importantes de alienación, ya sea religiosa falalista y fundamentalista, ya sea de beneficiarios de reformas y opciones o apoyos políticos, ya sea por los vínculos precapitalistas de colonos con los propietarios $\multimap$ gremialistas con los palronos artesanos- ya sea de remembranza de situaciones percibidas como mejores con el dueno de la finca antes de la reforma agraria y la constitución de cooperativas de producción manejadas o controladas muchas veces por funcionarios externos. Para los desempleados y subempleados, por su parle, la percepción de la realidad objeliva está dividída enfre la interpretación fatalista, la predisposición al servilismo humillante, o la interpretación más correcta de la realidad. La percepción, en fin, que tienen Tos desplazados y refugiados, si no es de fatalismo resignado en muchos casos, sólo es de lemporalidad y transición a un relorno a las condiciones y siluación previas a la migración, adjudicando el origen de su problema más a la guerra que a las causas estruclurales de la misma y de su precariedad de vida (Instituto, 1985; 1986), victimas, por lo tanto, de una alienación que se va profundizando por la dependencia en la subsistencia, la instrumentalización de que son objelo, la manipulación sociopolítica, la articulación social progresiva al sistema en zonas de predominancia del mismo, y al indoctrinamiento a que se ven somelidos a través de sus hijos reclutados para el servicio militar. El caso de los que reciben remesas de familiares en los Estados Unidos, tan generalizado. los ubica en una situación de privilegio, percibłdo como tal, sin suliciente conciencia de la explolación a que se ven forzados sus familiares en el 
pais receplor, ni tampoco del nivel de explotación a que ellos mismos se ven sometidos en El Salvador por el mercado, en los bienes que adquieren, o por las agencias y personas tramitadoras de envios y cambio de moneda que logran pingües ganancias y exportan cuantiosos capilales y divisas al exterior gracias a ellos (Monles, 1987).

Pero es tal vez en las capas medias donde la percepción de la realidad puede estar más alienada e ideologizada (Montes, 1980, 171, 203-205). Gran parte de la fracción de la "intelligentsia" - con excepción de un amplio sector magisterial — no sólo no percibe la realidad de su ubicación en el sistema y en el modo de producción, como asalariados del mismo, sino que se perciben como privilegiados, independientes y creadores intelectuales de consenso o de una nueva sociedad, agradecídos, por lo mismo, al sislema y a las clases dominantes por la oportunidad que les brindan de desarrollar sus cualidades personales y de crear o difundir ideología: Entre los empleados, por su parte, existe una gran heterogeneidad en la percepción de su realidad objetiva, desde un allo nivel de conciencia correcta, hasla un máximo de alienación hacia el sistema y hacia los propietarios de los medios de producclón o hacia el estado-que denomina "empleados" a una parte del proletariado contratado por él-. que los distinguen, diversilican, gratifican y honran, sintiéndose parte importante, obligados a reproducir el sistema de domifiación hacia la clase trabajadora, convirtiéndose a veces en fanáticos instrumentos de explotación u opresión de la clase a la que estriclamente pertenecen y de la que han surgido. Los pequefios propietarios, on lin, predominantemente tienen una percepción distorsionada, incorrecta y alienada de la realidad objetiva, compartiendo la conciencia de propietarios y a veces aliados a los gremios empresariales, inconscientes del grado de explolación a que están sometidos por esos mismos a los que tal vez defienden y con los que se solidarizan.

La percepción de la realidad que tenga el lumpen es difícil de medir o conocer sin una investigación especílica. Si bien es de suponer que los jefes y dirigentes posean una conciencia correcla de su lugar y relaciones en el sistema, es presumible que la mayor parte de los integrantes de la base padezcan una profunda alienación, generada no sólo por el sislema mismo, sino profundizada e inducida, a veces por mecanismos de intimidación y chanlage, por la cúpula que dirige y controla esta capa social.

\section{Conclencla de clase y opclón consecuente:}

La conciencia de clase, que de alguna forma se ha insinuado ya en el apartado anterior, no es lo mismo que la percepción de la realidad, aunque si se basa en ella, al menos en la percepción correcta; tampoco es una consecuencia mecánica, automática e inevitable de la situación de clase y su pertenencia. Hay una conciencia de clase más de tipo estruc- 
tural, que se va forjando y consolidando con el desarrollo mismo del modo de producción y de las fuerzas sociales, que se maniliesla en la organización y luchas durante los periodos de relativa estabilidad sociopolitica -algo de esto se ha estudiado por diversos aulores: Menjivar, 1979; Cabamús, 1983; 1985; Cardenal 1985; Montes, 1984; 1986; entre otros.

La clase dominante es la que ha tenido una conciencia de clase totalmente consecuenle $y$ ha mantenido la unidad a su interior; si en las décadas de desarrollo y mayor prosperidad se mantenía latente, en los momentos en que ve amenazados sus intereses -como con ocasión del intento de "Transformación Agraria" - se revif́aliza, unifica y pone en funcionamiento todos los mecanismos de presión, de instrumentalización del aparato del eslado y de la inslitución armada, y exige la implementación de estrategias de represión y lerror contra los que atentaran a sus intereses (ver ECA, sept.-oct. 1976 a diciembre 1979). En la clase dominada, por el contrario, la división, dicotomización de fuerzas, y la profunda alienación inducida secularmenle, son las caractéristicas predominantes, con pequefios grupos organizados, conscientes y luchadores por sus derechos, como excepción; en el proletariado urbano, por un lado, la sindicalización era minoritaria y, aun asi, dividida en múltiples asociaciones, federaciones y tendencias (Samayoa y Galván, 1979; Montes, 1984, 173 y ss.); en el campo, a su vez, la sindicalización estaba prohibida de hecho, y mientras los pequenos propietarios y los colonos mantenian los mayores niveles de alienación - absleniéndose de cualquier participación en organizaciones populares o, peor aún, sirviendo de base a la infraestructura de dominación y represión, como era ORDEN-. entre el semiproletariado y el proletariado rural la conciencia y la participación organizaliva se distribuia entre las organizaciones campesinas consecuentes y las de represión y cooptación (Cabarrús, 1983; 1985; Cardenal, 1985) -0 ante el inlento y debate de la "transiormación agraria" se mantenian pasivos o como simples espectadores los posibles beneficiarios (Montes, 1986, 147-174"). En las capas medias, a su vez, la división y la alienación propia de las mismas era lo predominante, con pequefias islas de conciencia y organización, principalmenle en el magislerio nacional, aglutinado primero en ANDES 21 de junio y luego consolidado por las luchas libradas, especialmente en las de 1971 (UCA, 1971), y en algunos reducidos grupos de los empleados públicos y bancarios, sobre todo - además de la peculiar y cónocida posición y opción de la universidad nacional.

El deterioro progresivo de las condiciones de vida por causa de las estructuras violatorias de los derechos económicos, sociales y cullurales de las grandes mayorias -estructuras de muerte (Montes, 1988a)-. agudizado por acontecimientos explosivos, provocados ellos mismos por tal deterioro, forzarian a una conciencia creciente y consolidación de las 
clases sociales o de los grupos más consecuentes y combalivos a su interior. La guerra con Honduras, el fracaso en la oblención de los objetivos propuestos, y las funestas consecuencias que se derivaron -repatriación de unos 100,000 campesinos y la subsiguiente presión sobre la tierra y el escaso mercado de trabajo, cierre de las Ironteras con Honduras y el aislamiento comercial de El Salvador-; los iraudes electorales de 1972 y 1977 -con el bloqueo a cambios políticos por via eleccionaria (Hernández-Pico y otros, 1973)-; el intento fallido de "Hransformación agraria" propuesto por el gobierno en 1976 y la ola de represión contra las incipientes y débiles organizaciones campesinas, la iglesia católica y otras cuantas instituciones $-y$ la correspondiente frustración de toda esperanza de cambios económico-sociales por la vla pacífica-; llevarian a un aglutinamiento mayor de la clase dominante amenazada, a la opción por la vla revolucionaria y armada a sectores de la "intelligentsia" y capas medias principalmente, al crecimiento y unificación progresiva de la organización popular en una parte del campesinado, al robustecimiento del proletariado urbano más consciente, y a un fortalecimiento y posterior alianza de sectores de las capas medias, desde el magisterio a grupos importantes de los intelectuales y empleados, con raices incluso en la instilución armada. Pero las grandes mayorlas, las masas no conscientes ni organizadas, se mantendrlan predominantemente a la especlativa, 0 pasivamente frente a los acontecimientos y Irente a la crisis en proceso de aceleración.

Sin embargo, creo que la conciencia de clase y la opción consecuente - la ausencia de ella y la acción contraria a la misma-, no sólo se vuelven más consistentes en la misma lucha de clases, sino que se manifiestan con más claridad en el comportamiento de las diversas fuerzas sociales en las coyunturas crilicas, lanto más en una crisis orgánica como la que experimenta el bloque histórico salvadoreno en el presente. Por tal razón, estimo que es interesante desarrollar con más extensión esle punto en la siguiente parte de mi trabajo.

\section{I.Anállsis coyuntural de las fuerzas soclales}

Se puede caracterizar la crisis salvadoreña actual como de "crisis orgánica", de acuerdo al análisis gramsciano (Portelli, 1978), no sólo ni tanto por la ruplura del vínculo entre la clase dominanle y los intelectuales orgánicos -primero por el golpe de estado del 15 de oclubre de 1979, luego por el paso de algunos intelectuales, militares y burócratas a los frentes revolucionarios (democrálicos o armados)-, que se podia recomponer -y en parte se recompuso-; sino por la disolución de la hegemonla a nivel de la sociedad en su conjunto. No se ha logrado reconstruir la sociedad civil ni lograr un consenso para toda la sociedad, dividida trente a dos proyectos antagónicos; mientras el bloque histórico en crisis 
pretende un consenso por medio de la ideologia antirrevolucionaria y a través de repetidas elecciones -que supuestamente deslegitiman la alternativa revolucionaria-, el bloque hislórico en formación busca también un consenso a través de un proyeclo y una ideologia acorde con los supuestos intereses de la clase dominada, y por medio de repelidas ofertas de diálogo-negociación; y ninguno de los dos bloques logra un consenso nacional. Pero lampoco se ha logrado reconstruir la sociedad política, como lo demuestra la vigencia de una guerra desatada por casi ya ocho años, la existencia de dos fuerzas beligerantes y armadas incapaces de aniquilar a la contraria en plazos previsibles, y la persislencia también de zonas bajo predominio de cada una de las partes -las proporciones diferenciadas o desiguales de ambas partes no son pertinentes, dado que son suficientes para no ser derrotadas y para desestabilizar a la contraria y al conjunlo de la sociedad e impedir la reconstrucción de una sola sociedad política.

\section{Explosión de la crisıs orgánlca:}

A mi juicio, el período nuclear de la explosión de la crisis orgánica no son los últimos meses de 1979, con el golpe de eslado y sus consecuencias, que tralaron de ser cooptadas por la clase dominante por medio de distintos mecanismos de presión, hasta conducir a la renuncia de la primera "junla revolucionaria de gobierno" y a la derechización de la institución armada (ECA, sept. 1979 a en.-feb. 1980; UCA, 1982). El nudo de la crisis se desata en los primeros meses de 1980:

1) la instilución armada, bajo presión norteamericana, se desliga de la clase dominante, se alía con la democracia cristiana, y se compromete a impulsar reformas en las estrucluras económicas -reforma agraria, bancaria y del comercio exterior-, al tiempo que opta por la guerra contrainsurgente y la militarización del país, reprimiendo no sólo a los grupos revolucionarios armados, sino a todas las organizaciones que los apoyen $y$ atenten contra la paz que se quiere imponer;

2) la clase dominanle -fracasada en el intento de recomponer la alianza con la institución armada para que defienda sin restricciones sus intereses - se aglutina y unifica, percibiendo la necesidad de crear nuevamenle los instrumentos propios de dominación y hegemonía -delegados en la institución armada y en la "clase gobernante auxiliar" desde 1931- por lo que necesita de un partido político que la represente y defienda sus inlereses en los poderes del estado - ya no le sirve el partido oficial, pues el de hoy está en otro tipo de alianza y adopta politicas que menoscaban la hegemonía de la clase dominante-, por lo que tras intenios de control y/o utilización de partidos preexistentes de derecha, se decide a crear ARENA, robustecerlo y lanzarlo a-la contienda política, primero para impedir el progreso de la reforma agraria en el perlodo 1982- 
84, luego para limitar su extensión y alcance en la nueva Conslitución Polílica, más tarde para controlar o neutralizar al ejecutivo y legislativo en las posibles medidas reformistas, finalmenle para tomar el poder legislativo y municipal en 1988 y aspirar al control del ejeculivo en 1989 y así recomponer todo el aparalo de dominación de clase por medio del estado; al mismo tiempo, creará sus propios mecanismos de coerción y recomposición de la sociedad política por medio de grupos militarizados, o por la presión, exigencia, ofertas y conlactos permanentes con la institución armada;

3) la clase dominada se lanza a las calles de San Salvador, primero a demostrar su cohesión y fuerza, el 22 de enero de 1980, tras la fundación de la Cordinadora Nacional (CN), con lo que toma conciencia de su gran número, diversidad de organizaciones, fracciones y capas que la integran, asi como del apoyo y simpatia que despierta en grandes sectores de la población, pero que al ser reprimida y masacrada - lanto en esa ocasión como en los funerales de Monsefior Romero-, toma conciencia de que no le dejan olra allernaliva que la via revolucionaria, y opta por la insurrección y la guerra popular prolongada, que requiere la incorporación, entrenamienlo y equipamienlo armado;

4) las capas medias se escinden en dos opciones opuestas: si fuertes e importantes conlingentes, tanto de "intelligentsia" como de "empleados" se unen a los Irentes revolucionarios -democrático o armado-. otro gran sector cree que la democracia cristiana representa sus intereses, es la expresión política de su "clase", y piensa que es posible una tercera vía, una tercera opción sustentada en la base social de las capas medias, carentes de estructura consistente, ni económica, ni militar, ni ideológica, ni social, sino puramente superestructural -en los niveles más abstractos de la superestruclura-, abocado a un repelido fracaso del intento -por más soporte y sustenlación que le den fuerzas externas e internacionales que cirran más los proyeclos en deseos voluntarísticos que en análisis estructurales (Montes, 1984).

A partir de ese momenlo, las pequeñas coyunturas que se van presentando, los reacomodos de fuerzas y alianzas, las pequefias conquistas y pérdidas de fuerzas sociales, los cambios en la cúpula del poder político civil o militar, los repetidos y fallidos intentos de reconstrucción del bloque histórico por diversos caminos, no han logrado reconstruir ni la sociedad civil ni la sociedad política, es decir, rehacer la hegemonia sobre el conjunto de la sociedad, y El Salvador permanece en una situación de crisis orgánica, manilestada en la guerra civil y en la falta de consenso nacional. Duranle lodos estos años las dos fuerzas sociales fundamentales - la clase dominante y propietaria de los medios de producción, y el movimiento revolucionario que reivindica la representatividad de la clase dominada y la delensa de sus inlereses- se han ido unificando, 
fortaleciendo y consolidando, librando su lucha no sólo contra el adversario, sino en conquistar la alianza y apoyo de los "sectores medios" - mientras una buena parte de éslos se oblina en ir conlra la historia y el comportamiento o límites de las estructuras, para convertirse en el núcleo y la base de un nuevo bloque histórico (Montes, 1984). Si desde una perspectiva leórica y de aplicación universal las "capas medias" son incapaces de constituirse en verdadera clase social - mucho menos de ser la clase lundamental sobre la que se estructure un nuevo bloque histórico (Montes, 1980) - en El Salvador es aún más quimérico, dada la reducida participación cuantilaliva en la estruclura de clases - como se ha visto ya-, dada la gran concenlración de la propiedad en una inlima cúpula demográfica, y dada lambién la polarización exlrema entre las clases en los niveles sociales, ideológicos y bélicos; pensar en las "capas medias" como núcleo y clase social fundamental para una alternaliva distinta de reconstruir un bloque histórico es no sólo inviable sino imposible; a lo más se podrá lograr una alianza y/o unión estralégica de diversas fuerzas sociales, que se constiluyan en grupo de presión, e incluso en un fuerte movimiento social hacia la obtención de la paz y de la solución política al conilicto a través de un más amplio consenso en un proyeclo que no lesione fundamentalmenle los inlereses de las clases y capas sociales que componen la estructura, si es que eso es posible.

\section{Comportamlento de las clases soclales}

El grado de conciencia de cada una de las clases sociales, de sus tracciones y demás divisiones, de alguna manera se puede medir y captar a través del comporlamiento y opciones que adoptan frente a diversos acontecimientos a lo largo de la crisis orgánica. Hasla diciembre de 1983 básicamenle lo he estudiado y analizado en el trabajo ya citado (Montes. 1984). Aqui pretendo exponer brevemenle algunos elemenlos analiticos complemenlarios y afhadir algunos hechos y comporlamientos principales ocurridos en los casi cinco ańos últimos.

La clase dominanle ha seguido unificándose, tortaleciéndose y consolidándose, tanto a nivel de intereses económicos, por medio del liderazgo de las instiluciones gremiales de la empresa privada y por medio de la lucha sostenida en contra de las medidas reformistas y a favor de sus intereses, como a nivel polílico por medio del partido ARENA, que ha ido incrementando su poder político, hasla conquistar la mayoría en la asamblea legislativa y en los concejos municipales en 1988, y se prepara a dar la batalla final para el control lolal del aparalo del estado en 1989, con lo que pretendería reconslruir la hegemonia sobre la sociedad y restaurar el bloque histórico que le favorece, si es que ello dependiese sólo de la detentación de esa cuota del poder político.

La vanguardia revolucionaria de la clase dominada, por su parte, no 
sólo mantiene la guerra de insurgencia y se robustece militarmente, sino que ha logrado mantener la base social necesaria para enirentar al adversario y sus fuertes e inagotables apoyos bélicos, económicos, ideologicos y políticos, y se ha impuesto de hecho como una fuerza sociopolitica que debe ser lenida en cuenta en el proceso salvadoreño y que tiene que participar en diálogos para la solución de la crisis. El crecimiento acelerado y consistente de la base social insurgenle se vio delenido por la estralegia contrainsurgente, por las decenas de miles de asesinados de la población civil y el terror subsiguiente creado en la población. por el exilio de más de un millón de salvadorefios -en gran parte hostiles al régimen imperante, y simpatizanles o apoyo del movimienlo revolucionario (especialmente entre los emigrados al área mesoamericana)-, por la cooplación de una parte del campesinado beneficiario de la reforma agraria, y por la despolitización y pasividad de una buena proporción de los desplazados internos, que huyeron de la guerra, pero su presencia en zonas controladas por el gobierno, su dependencia de la ayuda para subsistir, su permeabilidad a la sistemálica campaña de propaganda ideológica del sistema, asl como por el conflicto interno creado con la militarización de sus hijos $\rightarrow$ l subsidio económico proveniente de sus salarios castrenses, la mentalización trasmitida, e incluso las consecuencias de muerte y lesiones de guerra que inculparán no sólo a la institución armada que los forź́ a combalir, sino a los insurgentes que les causaron flsicamenle los danos-, los pone del lado del régimen, o cuando menos pasivos y "neutrales" en el conflicto - la previsión para el futuro de esa gran masa de desplazados, principalmente en las nuevas generaciones, es que se vean arrojados a integrar el hasta ahora reducido "lumpen", por el trauma vivido, su carencia de capacilación para la nueva vida a que se han visto forzados, la incapacidad del sistema de integrarlos laboral y socialmente, y la experiencia degradante de la dependencia e instrumentalización que deteriora el respeto y la imagen que puedan tener de si mismos, lo que modificaría sustancialmente la estruclura social salvadorena con tamana derivación hacia la capa infima (una atención especial debe irse prestando al proceso social de la masa creciente de mutilados de guerra y licenciados del servicio militar, para ver si son incorporados a la vida productiva y social, o son forzados también a incrementar el "lumpen"). Por otro lado, las organizaciones sociales y laborales simpatizantes o solidarias con la insurgencia, no sólo han sido deslegitimadas y combatidas ideológicamente por el régimen, sino que han sido objetos focales de represión, disolución y debilitamiento permanente. Sin embargo, el movimiento insurgenle ha creado nuevas formas de vinculación y alianza o apoyo en la clase dominada y en las capas medias, alabando, apoyando o secundando la recomposición de bases sociales consecuentes, que a medida que se iban desgasiando generaban otras nuevas - desde la CRM hasta el Comilé 10. de mayo, la CST, UNTS, 
Es en el "proyecto alternativo de centro" donde se observa mayor inconsistencia y menor continuidad -acorde con los condicionamientos estruclurales a que ya se ha hecho referencia-; la carencia de una clase social estrictamente tal como base, pretende ser suplida con alianzas de Iracciones y sectores, principalmente nucleados en tomo a las "capas medias"; pero la incapacidad de resolver los problemas y especlativas, tanto económicas como sociales, y de solucionar la guerra, lleva a conlinuas frustraciones, desarticulaciones y esfuerzos de recomposición permanente - ya sea a través de "pactos sociales" con la UPD, con la UNOC, el COC, o con las cooperativas de la reforma agraria (instrumentalizadas en muchas oportunidades como base social del proyecto contrainsurgente y "de centro", presionadas por la inseguridad del fuluro y por la gestión burocrática y la deuda agraria)-; pero la misma organización, libertad brindada y fracaso en cumplir las promesas -además de la manipulación político-ideológica constante, ya sea de parte del mismo régimen, ya sea de instancias exlernas como el IADSL (Casper, 1986)les conducen a cierta toma de conciencia, pugna por sus intereses, deserción y crisis en la base social, y a la indispensable nueva articulación, manipulación y cooplación de las luerzas sociales y laborales que apoyen al régimen.

Para concluir este apartado, estimo necesario analizar brevemente un fenómeno que puede llamar la atención en la dinámica de diversas fuerzas sociales en este proceso salvadoreño: el surgimiento, escision, composición, disolución, recomposición de diversas organizaciones, ya sean de apoyo al intento de creación de un bloque de centro, ya sean de opción más consecuente de clase. La explicación del hecho la encuentro predominantemente en la misma crisis orgánica que padece la sociedad salvadorefia, en la aguda polarización creada por la misma y por las luerzas lundamentales de los dos intentos de bloque histórico antagónicos, así como en el de construir uno alternativo de centro, y en la lucha de ellos por conquistar a las diversas fuerzas sociales para ampliar su base y alianza en la reconstrucción o en la consinucción del bloque histórico. La consecuencia de lo anterior es el desgaste sistemálico y permanente de las diversas organizaciones aliadas, de los pactos y alianzas, por dos vias concurrentes: una es el ataque y la batalla constante a que están sometidas por la campaña ideológica, física y sicológica acusadora de ser instrumento y/o fachada de la insurgencia - mientras las aliadas al "intento de bloque de centro" son atacadas por la derecha considerando a ésle una mediación para el triunio de la izquierda maxistaleninista, y por la izquierda como mediación e instrumento del proyecto imperialista-, además de la presión y estuerzo constante de los grupos hegemónicos en cada proyecto por radicalizar, instrumentalizar y sub- 
sumir a dichas organizaciones, subordinando a lo polílico su autonomía e identidad laboral o gremial; la otra es el tracaso, lanlo en la consecución de los objetivos laborales y/o gremiales propios, como en la solución de la crisis orgánica, lo que conduce a unos a la radicalización que justifica y legilima las acusaciones y alaques de la primera via, y a otros a la desilusión y la deserción; en todo caso, a la desnaturalización y desgasle de la organización, en sus objelivos, y como instrumento de solución de la crisis orgánica. Sin embargo, dado que la crisis se mantiene irresoluta, y que las condiciones de vida se deterioran para las grandes mayorias y para el sector organizado, el mismo proceso exige y fuerza al surgimiento de nuevas instancias, a la recomposición de fuerzas y a la constilución o reconstrucción de alianzas.

\section{Las masas no organlzadas:}

Las grandes mayorias de la población, sin embargo, permanecen desarticuladas, inorganizadas, y sin medios propios de expresión y lucha por la defensa de sus intereses, y sólo pueden expresarse en conladas oportunidades, ya sea que se les consulte direclamente, ya sea que den su opinión indireclamente a través del voto electoral. Por lo que se refiere a la primera vía, repetidamente se expresan en el sentido de que la crisis económica y la guerra son los problemas que sienten como más graves y que les urge sean resuellos a través del diálogo o por otro camino racional (Marlin Baró, 1987; IUDOP, 1986-1988). En cuanto a la segunda via, las elecciones, se aprecia una disminución creciente en la participación popular, lo que no se puede alribuir exclusivamente al desgaste del método como expresión de la volunlad popular y como camino de solución a la crisis del pais, pero que probablemente también está influido por ello (Montes, 1985; 1988). De acuerdo a los resultados de las últimas elecciones, en marzo de 1988 aproximadamente 1,100,000 salvadorefios residentes en el país y en edad de volar no concurrieron a las urnas - ya fuera que no se empadronaron $(300,000)$, o que empadronados no obluvieron el carnel electoral (olros 300,000 ), o que teniendo carnel no fueron a volar (otros 500,000 ; todas las cirras de acuerdo a los datos oficiales del CCE)-, lo que representa casi la misma cantidad de los volos emitidos; pero 220,000 volos no fueron válidos, lo que hace que los votos válidos apenas superen el $40 \%$ de los posibles (Montes, 1988). Si se excluyen los que tuvieron dilicultades concretas en el empadronamienlo o en la obtención del carnel electoral, o los que se vieron impedidos por temor o por carencia de transporte el dia de las elecciones, lodavía queda un elevado porcentaje que se absluvo de volar por propia voluntad -más el $19 \%$ que en su mayoria no halló en la restringida oferta politica opciones que les satislicieran o que presentaran perspeclivas de resolver los problemas fundamenlales que alectan a la sociedad en su conjunto. 
Sin embargo, en las mismas elecciones se puede percibir el grado de conciencia y de alienación de las clases sociales, de sus fracciones y capas o demás subdivisiones. En la medida en que sean válidos los datos correspondienles a cada una de las clases y fracciones, no se puede entender que el partido ARENA, representante de los intereses de la clase dominante, que cuenta entre un $0.3 \%$ y menos del $7 \%$ de la población, pueda oblener casi medio millón de votos -el $48.1 \%$ de los válidos, $38.9 \%$ de los emitidos, y $17.9 \%$ de todos los supuestamenle posibles (cilras que superan incluso la suma de la clase dominante y de las capas medias)-, a no ser que una elevada proporción de componentes de olras clases sociales y fracciones (muchos de ellos pertenencientes a la clase dominada) se hayan plegado a esa opción ideológico-política ajena y conlraria a su exlracción de clase (Monles, 1988, 182-184). Pero tampoco se entiende que el partido demócrala cristiano, exponente y representante de las "capas medias" - que en el mejor de los casos concentran entre el $10 \%$ y menos del $26 \%$ de la población-, haya podido oblener en las elecciones de 1985 más de medio millón de votos válidos (el $52.35 \%$ de los mismos), y en 1988 más de $300,000-35.1 \%$ de los válidos, $28.4 \%$ de los volos emitidos, y $13.1 \%$ de los supuestamente posibles (Ibidem)-, a no ser que también algún porcenlaje de los integrantes de la clase dominada haya sido víclima de la alienación de creer que en un partido que responde a los intereses e ideología de las "capas medias" y del proyecto norteamericano puede atender a sus necesidades e intereses y resolver los problemas del pais en beneficio de las grandes mayorías -si bien en las elecciones de 1988 se ha moslrado que el proceso y la experiencia bajo la conducción política de la democracia cristiana ha despertado cierta conciencia en medios populares, a no ser que se haya profundizado la alienación de clase social en algunos de ellos que se hayan pasado a votar por ARENA, no para "agudizar las contradicciones", sino con la esperanza de encontrar ahi palialivos a su siluación y a la crisis del país.

\section{Perspectlvas}

Dada la actual correlación de fuerzas, tanto internas como internacionales, no es previsible que se modilique suslancialmente la estructura social salvadorena; no ya por el triunfo de un proceso revolucionario. pero tampoco por una serie de reformas y reacomodos - tanto menos con la consolidación de la clase dominante y de su expresión política en ARENA, y la previsible conquista del poder político en el ejecutivo, 0 de la capacidad, cuando menos, de ejercer desde la Asamblea Legislativa fuertes presiones en defensa de sus intereses de clase.

Tampoco se prevé que la guerra civil tenga una solución a corto y previsible plazo, ni militar ni política. Si los personeros norleamericanos 
pronostican un perlodo de seis a ocho años más para lograr una supremacla clara e irreversible del ejército sobre los insurgenles, y éstos cada vez sostienen más consistentemente la tesis de la "guerra popular prolongada" - y la posibilidad de una "insurrección popular" no se ve corno realista-; quiere decir que la solución por la vía militar no se vislumbra para ninguna de las partes. Por su lado, la solución política, por la vla del diálogo y la negociación, se va postergando indefinidamente, sin abordarla en serio y con profundidad, y la aclual correlación de fuerzas inlernas no le es más favorable - a no ser que haya una presión en tal sentido por la administración norteamericana, si es que triunfara el partido demócrata y adoplara esta polílica hacia la región, o que la participación de la "Convergencia Democrática" en las elecciones presidenciales de 1989 atrayera una gran afluencia de votantes que presionen a compromisos políticos en esa dirección.

Una alternativa para salir del impasse tendría que pasar por la toma de conciencia auténtica en los integrantes de las fracciones y demás subdivisiones, tanto de las "capas medias" como, sobre lodo, de la clase dominada, despojándose de la alienación introyectada, para alcanzar una coordinación estratégica de las diferentes fuerzas sociales que las componen o emanan de ellas, de manera que se conviertan en una gigantesca fuerza de presión, en un movimiento social mayoritario que exija la paz y los cambios estructurales indispensables para la salisfacción de las necesidades básicas y la garantia de lodos los derechos humanos de las grandes mayorlas.

Si la democracia es el sistema que se predica como válido y deseable, y si a la democracia se le llena del contenido de su propio significado etimológico, hay que reconocer que en EI Salvador nunca ha existjo una verdadera democracia real, que el pueblo nunca ha tenido el poder, pues la clase dominada, que constituye la inmensa mayoria, no sólo no lo ha detentado, sino que tampoco ha tenido un partido político que la represente, defienda sus intereses auténlicos y provenga de su seno. $\mathrm{Ni}$ los partidos políticos surgidos de la minúscula clase dominante pueden representar a las mayorias y defender sus inlereses realmente - sino, a lo más, hacerles simbólicas concesiones a cambio de sus votos-; ni tampoco los partidos surgidos y representativos de las pequenas y fraccionadas "capas medias" son auténticamente populares, representan ni defienden los intereses de la clase dominada, de las grandes mayorias populares - por más que se declaren y presenten como tales, en contra del análisis estruclural y de la praxis política concreta. La via democrática, real, pasa por la concientización y la articulación unilicada de las grandes mayorías, de la clase dominada - y de una parte de las capas medias que objetivamente pertenecen a esa clase aunque no lo perciban como tal-. para crear una expresión política propia y auténlica, un partido que la 
represente y defienda sus intereses reales y concrelos, para alcanzar la democracia real que se dice pretender, salvaguardando los derechos $\theta$ intereses de todos los ciudadanos, pero en primer lugar los de las grandes mayorias, del pueblo.

\section{BIBLIOGRAFIA UTIUZADA}

Cabamis, Cartos R.; GENESIS DE UNA REVOLUCION; MŚxico, Casa Chata, 1883.

-EI Salvador. De movimiento campesino a revolución popular"; en HISTORIA POLITICA DE LOS CAMPESINOS LATINOAMERICANOS (Pablo González Casanova, Coordinedor); México, 6. XXI, 1985, 77-115.

Cardenal, Rodollo; HISTORIA DE UNA ESPERANZA. Vida de Rutilio Grando; San Salvedor, UCA-Editores, 1985.

Colindres, Eduardo; FUNDAMENTOSECONOMICOS DE LA BURGUESIA SALVADORENA: San Salvador, UCA-Editores, 1977.

ECA; revista Estudios CentroAmericanos (ECA); San Salvador, UCA.

Gurvitch, Georges; TEORIA DE LAS CLASES SOCIALES; Móxico, EDICUSA, 1971.

Hernández-Pieo, J., y otros; EL SALVADOR: AÑO POLITICO 1971-72; San Salvedor, UCA, 1973

Instituto; EL SALVADOR 1985. DESPLAZADOS Y REFUGIADOS; San Salvador, UCA, Instituto de Investigaciones, 1985.

EL SALVADOR 1986. EN BUSCA DE SOLUCIONES PARA LOS DESPLAZADOS; San Salvador, UCA, Instituto de Investigaciones de Instituto de Derechos Humanos (IDHUCA), 1986.

IUDOP; Informes varios sobre diversos sondeos de opinion; San Salvador, Institule Universitario de Opinión Pública de la UCA (IUDOP), 1986-1988 (mimeo).

Lenin, V.I.: "Una gran iniciativa"; en OBRAS ESCOGIDAS, Vol. 3, 233-254: Moscú, Progreso, 1961.

Martin Baro, Ignacio; ASI PIENSAN LOS SALVADOREÑOS UABANOS (1986-1987); San Salvador, UCA-Editores, 1987.

Menjlvar, Refael; FORMACION Y LUCHA DEL PROLETARIADO INDUSTRIAL SALVADOREÑO; San Salvador, UCA-Editores, 1979.

Montes. Segundo; "Reflexiones sobre las 'clases medias"; en BOLETIN de Ciencias Econónicas y Sociales, abril 1980, 171; San Salvador, UCA, 1980.

"La supuesta neutralidad de le ciencia"; ibidem, junio-diciembre 1980, 203-205.

"¿Cuál es el modo de producción dominanie en El Salvador?"; (y "Critica a una caltica"); ibidem, enero-lebrero 1983,30-37 (y mayo-junio 1983, 231-235).

EL SALVADOR: LAS FUERZAS SOCIALES EN LA PRESENTE COYUNTURA (enero $1980 \mathrm{a}$ diciembre 1983); San Salvador, UCA, 1984.

"Las elecciones del 31 de marzo"; en revista ECA, abril 1985, 215-228; San Salvador, UCA, 1985.

EL AGRO SALVADOREÑO (1973-1980); San Salvador, UCA-Editore6, 1986.

"El Salvador: la tierra, epicentro de las crisis"; en BOLETIN de Ciencias Econónicas y Sociales, julio-agosto 1986, 240-256; San Salvador, UCA, 1986 a.

SALVADOREÑOS REFUGIADOS EN LOS ESTADOS UNIDOS; San Salvador, UCA, instituto de Investigaciones, 1987.

"Las elecciones del 20 de marzo de 1988"; en revista ECA, marzo-abril 1988, 175-189; San Salvador, UCA, 1988.

Montes, S., Meléndez, F. y Palacios, E.; LOS DERECHOS ECONOMICOS, SOCIALES Y CULTURALES EN EL SALVADOR; San Salvador, UCA (IDHUCA), mayo 1988a.

PCS; FUNDAMENTOSYTESIS DELALINEA GENERAL DELPARTIDOCOMUNISTA DEEL SALVADOR; en Fundamentos y Perspectivas, Revista teórica del PCS, San Salvador, 
CNP. junio de 1980.

PERA; V EVALUACION DEL PROCESO DE LA REFORMA AGRARIA; San Salvador, MAGOSPA-PERA, DOC. PERA-1-07-85, diciembre 1985 (mimeo).

Portelli, Hugues; GRAMSCI Y EL BLOQUE HISTORICO; México, s. XXI, 1978 (12a.).

Samayoa, S. y Galván, G.: "El movimiento obrero en El Salvador ¿resurgimiento o agitación ?*; en revista ECA, julio-agosto 1979, 591-600;San Salvador, UCA, 1979.

El cierre patronal de las empresas: prueba de fuego para el sindicalismo revolucionario en El Salvador'; ibidem, septiembre 1979, 793-800.

Sermeño L., José A.; "Comportamiento reproductivo de la juventud. El caso de El Salvador (a publicarse en ECA, junio 1988); San Salvador, enero 1988 (mimeo)

Sevilla, Manuel; "Visión global cobre la concentración económica en EISalvador; en BOLETIN de Ciencies Económicas y Sociales, mayo-junio 1984, 155-190; San Salvador, UCA, 1984.

Thome, Joseph R.; "Reforma Agraria en El Salvador'; ibidem, julio-agos to 1984, 235-253; San Salvador, UCA, 1984.

UCA; ANALISIS DE UNA EXPERIENCIA NACIONAL (ANDES - MINISTERIO DE EDUCACION): San Salvador, UCA, 1971.

EL SALVADOR: ENTRE EL TERROR Y LA ESPERANZA. Los sucesos de 1979 y su impacto en el drama salvadoreño de los años siguientes. San Salvador, UCA-Editores, 1982. 